\title{
Direct analysis of Peucedanum palustre samples by desorption atmospheric pressure photoionization-mass spectrometry
}

\section{Yrjönen, Teijo}

2017-06

Yrjönen , T , Vuorela , H \& Kauppila , T J 2017 , ' Direct analysis of Peucedanum palustre samples by desorption atmospheric pressure photoionization-mass spectrometry ' ,

Phytochemistry Letters, vol. 20 , pp. 49-53 . https://doi.org/10.1016/j.phytol.2017.04.001

http://hdl.handle.net/10138/307595

https://doi.org/10.1016/j.phytol.2017.04.001

cc_by_nc_nd

acceptedVersion

Downloaded from Helda, University of Helsinki institutional repository.

This is an electronic reprint of the original article.

This reprint may differ from the original in pagination and typographic detail.

Please cite the original version. 


\title{
Direct analysis of Peucedanum palustre samples by desorption atmospheric pressure photoionization-mass spectrometry
}

\author{
Teijo Yrjönen, ${ }^{a}$ Heikki Vuorela, ${ }^{a}$ Tiina J. Kauppila, ${ }^{\text {* }}$
}

${ }^{a}$ Drug Research Program, Division of Pharmaceutical Biosciences, Faculty of Pharmacy, P.O. Box 56, FI-00014 University of Helsinki, Finland

${ }^{\mathrm{b}}$ Drug Research Program, Division of Pharmaceutical Chemistry and Technology, Faculty of Pharmacy, P.O. Box 56, FI-00014 University of Helsinki, Finland

* Corresponding author.

Tel.: +358294159169

E-mail address: tiina.kauppila@helsinki.fi 


\begin{abstract}
Desorption atmospheric pressure photoionization (DAPPI) is an ambient mass spectrometry (MS) technique that can be used for the analysis of polar and nonpolar compounds directly from surfaces. Here, the feasibility of DAPPI-MS in the screening of plant metabolites from dried Peucedanum palustre leaves and umbels was studied. DAPPI-MS requires no prior sample preparation or chromatographic separation, and the analysis can therefore be performed directly from the untreated plant material. P. palustre contains several linear and angular furanocoumarins, some of which are specific for the species. The DAPPI mass spectra of both leaf and umbel samples showed distinct ions at $m / z 445$ and 443 in positive and negative ion modes, respectively. $\mathrm{MS}^{2}$ analyses of these ions confirmed that the ions were the protonated and deprotonated molecules, respectively, of peulustrin and its isomers, which have only been identified from $P$. palustre. The direct analysis of dried plant material by DAPPI-MS was shown to provide a fast and reliable means to confirm the identity of plant materials, to study the metabolite profiles of plants, and to screen biologically relevant compounds from plant surfaces.
\end{abstract}

\title{
Keywords
}

Desorption atmospheric pressure photoionization-mass spectrometry, Peucedanum palustre, milk parsley, furanocoumarin, peulustrin 


\section{Introduction}

Since 1950s, the analysis of primary and secondary metabolites from plants has relied on various chromatographic separation methods coupled to spectroscopic detection (Marston and Hostettmann, 2009). Especially, the analysis of secondary metabolites, defence and signalling compounds of plant kingdom, has been in the centre of attention due to their many interesting pharmacological properties. However, the complex nature of plant extracts has posed a major challenge in the analytical work and is the main reason for the need to combine one or several separation steps before the detection technique. These steps add complexity and slow down the analysis procedure, and risk alteration of the sample.

In recent years, direct mass spectroscopic methods have gained increasing attention in natural product chemistry (Wolfender et al., 2015). These methods include ambient mass spectrometry (MS), and techniques such as desorption electrospray ionisation (DESI) (Takáts et al., 2004) and direct analysis in real time (DART) (Cody et al., 2005). In DESI, a spray of charged micro-droplets is directed to the surface under study, where analyte molecules are picked-up by the droplets and subsequently ionized. In DART, a hot gas stream activated by plasma discharge is used to desorb and ionize analytes from the sample surface. The main advantages of these methods are the lack of sample preparation and the short analysis time. Some reports on the use of these techniques in the analysis of plant samples have been published so far: DESI has been used for analysis of alkaloids from poison hemlock (Conium maculatum), jimsonweed (Datura stramonium) and deadly nightshade (Atropa belladonna) (Talaty et al., 2005), monitoring of the fermentation of tea leaves (Fraser et al., 2013) and analysis of camptothecin from Nothapydetes nimmonia (Srimany et al., 2011), while DART has been used for the analysis of volatile organic compounds in Piper betle, eucalyptus and Bergenia crassifolia (Bajpai et al., 2012; Chernetsova et al., 2012; Maleknia et al., 2009). 
Desorption atmospheric pressure photoionization (DAPPI) is an ambient mass spectrometric technique that is efficient in detection of both polar and nonpolar compounds from surfaces (Haapala et al., 2007). DAPPI uses a microchip heated nebulizer, which provides a confined jet of vaporized dopant to desorb and vaporize analytes from the sample surface. Photons emitted by a krypton discharge lamp then initiate the ionization of analytes in the gas-phase similarly as in atmospheric pressure photoionization (Kauppila et al., 2002; Luosujärvi et al., 2008). In comparisons with DESI and DART, DAPPI has been shown to be more sensitive towards low polarity compounds (Haapala et al. 2007; Suni et al. 2012; Räsänen et al. 2014), less susceptible towards matrix effects than DESI (Suni et al., 2011) and have lower background noise than DART (Räsänen et al., 2014). In plant analysis, DAPPI has an advantage towards e.g. DESI and DART, since many of the natural compounds present in plant material are of low polarity. DAPPI can therefore detect a wider range of plant metabolites than other ambient MS methods. For the analysis of plant material by DAPPI, the sample is fixed on a glass microscope slide using double-sided tape, and analyzed as such (Fig. 1). In the analysis of natural compounds from plant surface, DAPPI-MS has been shown to be suitable for the analysis of cannabinoids from Cannabis sativa blooms (Kauppila et al., 2008, 2013) and cathinone and cathine from Catha edulis (khat) leaves (Kauppila et al., 2011). DAPPI has also been used for the direct analysis of pesticides from plant material (Vaikkinen et al., 2015).

Milk parsley, Peucedanum palustre (L.) Moench, is an umbelliferous plant growing in wetlands and damp environments in most parts of Europe (Meredith and Grubb, 1993). It contains a wide array of linear and angular furanocoumarins, as well as some simple coumarins (Eeva et al., 2004; Harborne, 1982; Yrjönen et al., 2016). These coumarins are thought to play a role in the defence of the plant against various environmental stress factors (Hadaček et al., 1994; Ojala et al., 1999; Siskos et al., 2008) and some of them also possess various pharmacological effects (Lim et al., 2014; Pae et al., 
2002; Sancho et al., 2004). It has been shown that some of these coumarin compounds are characteristic for a certain Peucedanum species, or their presence is limited to only a couple of species (Harborne, 1982). The coumarin composition of Peucedanum species can therefore be used to confirm the identity of a particular species or to aid the chemotaxonomic classification of the genus.

The aim of this study was to evaluate the feasibility of the DAPPI technique to the screening and identification of the main coumarins from dried $P$. palustre plant material.

\section{Results and discussion}

Dried leaf and umbel samples of $P$. palustre were analysed by DAPPI-MS without any pretreatment steps. Both positive and negative ion modes with either acetone or toluene as the dopant were used. In positive ion mode a prominent ion was observed at $m / z 445$ with both dopants (Fig 2). Note that as the double-sided tape used in the study did not give any background ions to the DAPPI spectrum, it was not necessary to subtract the background. This ion is likely to be the protonated molecule $\left([\mathrm{M}+\mathrm{H}]^{+}\right)$of peulustrin and its isomers. Peulustrin (Fig. 3) and its isomers are furanocoumarins that are characteristic to $P$. palustre, and have not been found in any other plants in the genus or family. Furthermore, these isomers are the main components in Finnish P. palustre specimens constituting approximately $50 \%$ of the total coumarin concentration in the aerial plant parts (Yrjönen et al., 2016).

With acetone dopant, the base peak was observed at $\mathrm{m} / \mathrm{z}, 229$; in addition, notable ions were observed at $m / z$ 329, 367, 205 and 163 (Fig. 2). The ion at $m / z, 329$ is likely the $[\mathrm{M}+\mathrm{H}]^{+}$ion of columbianadin and its isomer. Columbianadin (Fig. 3) is an angular furanocoumarin, which has been found in Peucedanum and Angelica genus plants (Chen et al., 1995; Harborne, 1982; Skalicka- 
Woźniak et al., 2009). The ion at $m / z, 229$ is likely to be a fragment of peulustrin or columbianadin, as it was also observed in the product ion spectra of the corresponding precursors (Table 1). The ions at $\mathrm{m} / z$ 367, 205 and 163 were especially high in umbels, and they were thought to be the $[\mathrm{M}+\mathrm{H}]^{+}$and fragments of umbelliprenin. Umbelliprenin (Fig. 3) is a prenylated simple coumarin umbelliprenin, which is one of the major coumarin components in the leaves and umbels of $P$. palustre (Yrjönen et al., 2016). It has been isolated also from $P$. arenarium Waldst. \& Kit., $P$. oreoselinum (L.) Moench (Harborne, 1982) and P. zenkeri Engl. (Ngwendson et al., 2003). Although DAPPI cannot be used for absolute quantitation of the analytes, the hights of the ions in the spectrum can be taken as indicators of the relative proportions of the compounds within the sample.

When using toluene as the dopant, a minor molecular ion $\left(\mathrm{M}^{+\cdot}\right)$ of peulustrin at $\mathrm{m} / \mathrm{z} 444 \mathrm{was}$ detected in addition to the $[\mathrm{M}+\mathrm{H}]^{+}$ion at $m / z, 445$, and instead of the fragment ion at $m / z 229$, a fragment at $m / z 228$ was observed. In previous DAPPI work it has been shown that toluene as the dopant promotes the ionization of analytes through charge exchange, and therefore the formation of $\mathrm{M}^{+} \cdot$ type ions (and their fragments) is more likely with toluene than with acetone (Haapala et al., 2007; Kauppila et al., 2008, 2013). Also, compounds of low polarity are typically more efficiently ionized with toluene than with acetone. The product ion at $m / z 228$ is suggested to have formed from the $\mathrm{M}^{+\cdot}$ ion, since protonated molecules and molecular ions formed in DAPPI have previously been shown to fragment through different mechanisms (Kauppila et al., 2013). This can sometimes be utilized in structural identification of the analyte. The $[\mathrm{M}+\mathrm{H}]^{+}$ion of columbianadin and its isomer at $m / z 329$, or the ions due to umbelliprenin, were not detected with toluene. Instead, intense ions at $m / z 401,383$ and 365, probably originating from dihydroxylated sesquiterpene coumarins, were observed (Yrjönen et al., 2016). 
DAPPI-MS ${ }^{2}$ product ion spectra of precursor ions at $\mathrm{m} / \mathrm{z} 329,367,401$, and 445 in positive ion mode are presented in Table 1 . The $\mathrm{MS}^{2}$ analysis of precursor ion at $m / z, 329$ yielded a product ion at $m / z 229$, corresponding to the cleavage of angelic acid or its isomer to form a columbianetin core structure. The same product ion at $\mathrm{m} / \mathrm{z} 229$ due to columbianetin was also observed in the $\mathrm{MS}^{2}$ spectrum of the precursor ion $\mathrm{m} / \mathrm{z} 445 . \mathrm{MS}^{2}$ analysis of the precursor ion at $\mathrm{m} / \mathrm{z} 367$ yielded main product ions at $m / z 205$ and 163 . For the precursor ion at $m / z 401$, intense product ions were observed at $\mathrm{m} / \mathrm{z}, 383,365,221,203$ and 163 . The identification of columbianadin and umbelliprenin was confirmed by comparing their $\mathrm{MS}^{2}$ product ion spectra to those of the corresponding standard compounds (Figure S1 in Supplementary material). Unfortunately, peulustrin standard was not available.The identification of columbianadin, umbelliprenin, and peulustrin and its isomers is in good agreement with previous HPLC-ESI-MS² experiments performed using the same plant material (Yrjönen et al., 2016). Also in the HPLC-ESI-MS² measurements, the peulustrin isomers were shown to be the main compounds in $P$. palustre leaves and umbels. However, the unknown ion at $m / z 401$ was only observed in the DAPPI measurements.

In negative ion mode the main ions were detected at $m / z 215$ and 443 (Fig. 2). In addition, minor ions were detected at $\mathrm{m} / \mathrm{z}, 161,367,451$ and 476; and with toluene also at $\mathrm{m} / \mathrm{z} 297$ (spectrum not shown). The ion at $m / z 443$ is suggested to be the deprotonated molecule ([M-H] $\left.]^{-}\right)$of peulustrin isomers, but the identities of the other ions are unknown (Table 1). In general, the negative ion DAPPI-MS of umbels yielded a much higher number of ions compared to the positive ion mode. The detected ions are likely due to acidic compounds, which are readily ionized in negative ion APPI (Kauppila et al., 2004), such as phenolic acids, flavonoids and organic acids, all abundant in Peucedanum species (Sarkhail, 2014). The DAPPI-MS ${ }^{2}$ product ions of the ion at $m / z 443$ in negative ion mode are shown in Table 1 . To our knowledge, this is the first report of the negative ion mode $\mathrm{MS}^{2}$ analysis of peulustrin and its isomers, and the proposed fragmentation pathway is 
described in Fig. 4. The peulustrin isomers appear to lose $\mathrm{CO}_{2}$ from the 2-pyrone ring of the coumarin core structure, and the side chain of the resulting molecule undergoes similar fragmentation as the intact deprotonated molecule. The cleavage of angelic, senecioic or tiglic acid moiety, depending on the isomer in question, results in the formation of fragment ions at $\mathrm{m} / \mathrm{z}, 361$, 343,317 and 299. The fragment ion at $\mathrm{m} / \mathrm{z} 227$ is suggested to be due to the columbianetin core structure.

DAPPI-MS was shown to provide a fast and efficient means for the identification of the main coumarins in $P$. palustre leaf and umbel samples. In positive ion mode, the diagnostic ion at $\mathrm{m} / \mathrm{z}$ 445 belonging to peulustrin isomers was easily detected regardless of the dopant used. The ion at $\mathrm{m} / \mathrm{z} 329$ originating from columbianadin was only detected using acetone as the dopant, and this would support the use of acetone in DAPPI-MS of $P$. palustre samples. This choice of dopant is further substantiated by the more intense ions at $\mathrm{m} / \mathrm{z}, 367,205$ and 163 resulting from umbelliprenin, when using acetone instead of toluene. However, because of the differences in the ionization mechanisms with these two dopants, a suitable dopant should be chosen case-specifically. In negative ion mode, the diagnostic ion of peulustrin isomers at $\mathrm{m} / \mathrm{z} 443$ was also clearly detected with both solvents facilitating the identification of the plant material. In general, mass spectra in negative ion mode with acetone and toluene dopants resembled each other more closely than in positive ion mode.

Peulustrin and its isomers are ideal marker compounds for the plant material, as they have only been identified from $P$. palustre and no other plant species, and since in our earlier study, peulustrin isomers were detected in all Finnish $P$. palustre samples in moderate to high concentrations (Yrjönen et al., 2016). Columbianadin was also detected in almost all plant samples, but in lower concentrations. DAPPI-MS could provide an efficient tool for the fast screening of natural 
compounds from plant material, or identification of plants based on characteristic compounds detected. The identification of compounds and separation of isobaric and isomeric compounds in DAPPI would be further facilitated by the use of high resolution mass spectrometry and/or ion mobility spectrometry.

\section{Experimental}

\subsection{Plant Material}

The same plant material that was previously used in the profiling of coumarins from P. palustre (Yrjönen et al., 2016) was used also in this study. Briefly, whole healthy flowering plants of $P$. palustre were collected from 43 sites in southern and central Finland in late July- early August 1988. The plants were identified by Ph. D. Pertti Uotila (Department of Botany, University of Helsinki, Finland) and different plant organs were then separated, dried, and stored at room temperature at the Division of Pharmaceutical Biosciences, University of Helsinki, Finland.

\subsection{Sample Preparation}

Dried umbels and leaves were fixed on a glass microscope slide using Fissaforte double-sided PE foam tape (Sicad group, Uboldo, Italy) and analysed as such using a custom-made DAPPI source (Fig. 1).

\subsection{DAPPI-MS Analysis}

In DAPPI, hot solvent vapour and nebulizer gas are delivered towards the solid sample using a heated nebulizer microchip, causing the thermal desorption of the analytes from the sample surface. Nitrogen was used as the nebulizer gas, and toluene and acetone as dopants. A krypton discharge VUV lamp was used to initiate the ionizing reactions. Agilent 6330 ion trap mass spectrometer (Agilent Technologies, Waldbronn, Germany) in positive and negative ion modes was used to 
measure the spectra. Nitrogen nebulizer gas flow rate was $180 \mathrm{~mL} / \mathrm{min}$ and dopant flow rate 10 $\mu \mathrm{L} / \mathrm{min}$. The DAPPI set-up and instrumentation have been described in detail by Haapala et al. (Haapala et al., 2007).

\section{Acknowledgements}

TJK wishes to acknowledge Academy of Finland (projects 218150, 255559 and 275089) for funding.

\section{References}

Bajpai, V., Pandey, R., Negi, M.P.S., Bindu, K.H., Kumar, N., Kumar, B., 2012. Characteristic differences in metabolite profile in male and female plants of dioecious Piper betle L. $\mathrm{J}$ Biosci 37, 1061-1066. doi:10.1007/s12038-012-9269-4

Chen, Y., Tsai, H., Wu, T., 1995. Antiinflammatory and Analgesic Activities from Roots of Angelica-Pubescens. Planta Med. 61, 2-8. doi:10.1055/s-2006-957987

Chernetsova, E.S., Crawford, E.A., Shikov, A.N., Pozharitskaya, O.N., Makarov, V.G., Morlock, G.E., 2012. ID-CUBE direct analysis in real time high-resolution mass spectrometry and its capabilities in the identification of phenolic components from the green leaves of Bergenia crassifolia L. Rapid Commun. Mass Spectrom. 26, 1329-1337. doi:10.1002/rcm.6226

Cody, R.B., Laramee, J.A., Durst, H.D., 2005. Versatile new ion source for the analysis of materials in open air under ambient conditions. Anal. Chem. 77, 2297-2302.

Eeva, M., Rauha, J.-P., Vuorela, P., Vuorela, H., 2004. Computer-assisted, high-performance liquid chromatography with mass spectrometric detection for the analysis of coumarins in Peucedanum palustre and Angelica archangelica. Phytochem Anal 15, 167-174. doi:10.1002/pca.764

Fraser, K., Lane, G.A., Otter, D.E., Harrison, S.J., Quek, S.-Y., Hemar, Y., Rasmussen, S., 2013. Monitoring tea fermentation/manufacturing by direct analysis in real time (DART) mass spectrometry. Food Chemistry 141, 2060-2065. doi:10.1016/j.foodchem.2013.05.054

Haapala, M., Pol, J., Saarela, V., Arvola, V., Kotiaho, T., Ketola, R.A., Franssila, S., Kauppila, T.J., Kostiainen, R., 2007. Desorption atmospheric pressure photoionization. Anal. Chem. 79, 7867-7872. doi:10.1021/ac071152g

Hadaček, F., Müller, C., Werner, A., Greger, H., Proksch, P., 1994. Analysis, isolation and insecticidal activity of linear furanocoumarins and other coumarin derivatives fromPeucedanum (Apiaceae: Apioideae). J. Chem. Ecol. 20, 2035-2054. doi:10.1007/BF02066241

Harborne, J.B., 1982. THE NATURAL COUMARINS: OCCURRENCE, CHEMISTRY AND BIOCHEMISTRY (Book). Plant, Cell \& Environment 5, 435-436. doi:10.1111/13653040.ep11611630

Kauppila, T.J., Arvola, V., Haapala, M., Pól, J., Aalberg, L., Saarela, V., Franssila, S., Kotiaho, T., Kostiainen, R., 2008. Direct analysis of illicit drugs by desorption atmospheric pressure photoionization. Rapid Commun. Mass Spectrom. 22, 979-985. doi:10.1002/rcm.3461 
Kauppila, T.J., Flink, A., Haapala, M., Laakkonen, U.-M., Aalberg, L., Ketola, R.A., Kostiainen, R., 2011. Desorption atmospheric pressure photoionization-mass spectrometry in routine analysis of confiscated drugs. Forensic Sci. Int. 210, 206-212. doi:10.1016/j.forsciint.2011.03.018

Kauppila, T.J., Flink, A., Laakkonen, U.-M., Aalberg, L., Ketola, R.A., 2013. Direct analysis of cannabis samples by desorption atmospheric pressure photoionization-mass spectrometry. Drug Testing and Analysis 5, 186-190. doi:10.1002/dta.1412

Kauppila, T.J., Kotiaho, T., Bruins, A.P., Kostiainen, R., 2004. Negative Ion Atmospheric Pressure Photoionization. J. Am. Soc. Mass Spectrom. 15, 203-211.

Kauppila, T.J., Kuuranne, T., Meurer, E.C., Eberlin, M.N., Kotiaho, T., Kostiainen, R., 2002. Atmospheric Pressure Photoionization. The Ionization Mechanism and the Effect of the Solvent on Ionization of Naphthalenes. Anal. Chem. 74, 5470-5479.

Lim, H.J., Lee, J.H., Choi, J.S., Lee, S.K., Kim, Y.S., Kim, H.P., 2014. Inhibition of airway inflammation by the roots of Angelica decursiva and its constituent, columbianadin. J Ethnopharmacol 155, 1353-1361. doi:10.1016/j.jep.2014.07.033

Luosujärvi, L., Arvola, V., Haapala, M., Pól, J., Saarela, V., Franssila, S., Kotiaho, T., Kostiainen, R., Kauppila, T.J., 2008. Desorption and ionization mechanisms in desorption atmospheric pressure photoionization. Anal. Chem. 80, 7460-7466. doi:10.1021/ac801186x

Maleknia, S.D., Teresa M. Vail, Robert B. Cody, David O. Sparkman, Tina L. Bell, Mark A. Adams, 2009. Temperature-dependent release of volatile organic compounds of eucalypts by direct analysis in real time (DART) mass spectrometry. Rapid Communications in Mass Spectrometry 23, 2241-2246. doi:10.1002/rcm.4133

Marston, A., Hostettmann, K., 2009. Natural product analysis over the last decades. Planta Med. 75, 672-682. doi:10.1055/s-0029-1185379

Meredith, T.C., Grubb, P.J., 1993. Peucedanum Palustre (L.) Moench. Journal of Ecology 81, 813826. doi: $10.2307 / 2261679$

Ngwendson, J.N., Bedir, E., Efange, S.M.N., Okunji, C.O., Iwu, M.M., Schuster, B.G., Khan, I.A., 2003. Constituents of Peucedanum zenkeri seeds and their antimicrobial effects. Pharmazie 58, 587-589.

Ojala, T., Vuorela, P., Kiviranta, J., Vuorela, H., Hiltunen, R., 1999. A bioassay using Artemia salina for detecting phototoxicity of plant coumarins. Planta Med. 65, 715-718. doi:10.1055/s-1999-14049

Pae, H.-O., Oh, H., Yun, Y.-G., Oh, G.-S., Jang, S.I., Hwang, K.-M., Kwon, T.-O., Lee, H.-S., Chung, H.-T., 2002. Imperatorin, a furanocoumarin from Angelica dahurica (Umbelliferae), induces cytochrome c-dependent apoptosis in human promyelocytic leukaemia, HL-60 Cells. Pharmacol. Toxicol. 91, 40-48.

Räsänen, R.-M., Dwivedi, P., Fernández, F.M., Kauppila, T.J., 2014. Desorption atmospheric pressure photoionization and direct analysis in real time coupled with travelling wave ion mobility mass spectrometry. Rapid Commun. Mass Spectrom. 28, 2325-2336. doi: $10.1002 / \mathrm{rcm} .7028$

Sancho, R., Márquez, N., Gómez-Gonzalo, M., Calzado, M.A., Bettoni, G., Coiras, M.T., Alcamí, J., López-Cabrera, M., Appendino, G., Muñoz, E., 2004. Imperatorin inhibits HIV-1 replication through an Sp1-dependent pathway. J. Biol. Chem. 279, 37349-37359. doi:10.1074/jbc.M401993200

Sarkhail, P., 2014. Traditional uses, phytochemistry and pharmacological properties of the genus Peucedanum: A review. Journal of Ethnopharmacology 156, 235-270. doi:10.1016/j.jep.2014.08.034

Siskos, E.P., Mazomenos, B.E., Konstantopoulou, M.A., 2008. Isolation and identification of insecticidal components from Citrus aurantium fruit peel extract. J. Agric. Food Chem. 56, 5577-5581. doi:10.1021/jf800446t 
Skalicka-Woźniak, K., Markowski, W., Świeboda, R., Głowniak, K., 2009. Computer-assisted searching for coumarins in Peucedanum alsaticum L. and Peucedanum cervaria (L.) Lap. Acta Chromatographica 21, 531-546. doi:10.1556/AChrom.21.2009.4.2

Srimany, A., Ifa, D.R., Naik, H.R., Bhat, V., Cooks, R.G., Pradeep, T., 2011. Direct analysis of camptothecin from Nothapodytes nimmoniana by desorption electrospray ionization mass spectrometry (DESI-MS). Analyst 136, 3066-3068. doi:10.1039/C1AN15339K

Suni, N.M., Lindfors, P., Laine, O., Östman, P., Ojanperä, I., Kotiaho, T., Kauppila, T.J., Kostiainen, R., 2011. Matrix effect in the analysis of drugs of abuse from urine with desorption atmospheric pressure photoionization-mass spectrometry (DAPPI-MS) and desorption electrospray ionization-mass spectrometry (DESI-MS). Anal. Chim. Acta 699, 73-80. doi:10.1016/j.aca.2011.05.004

Takáts, Z., Wiseman, J.M., Gologan, B., Cooks, R.G., 2004. Mass spectrometry sampling under ambient conditions with desorption electrospray ionization. Science 306, 471-473.

Talaty, N., Takáts, Z., Cooks, R.G., 2005. Rapid in situ detection of alkaloids in plant tissue under ambient conditions using desorption electrospray ionization. Analyst 130, 1624-1633.

Vaikkinen, A., Schmidt, H.S., Kiiski, I., Rämö, S., Hakala, K., Haapala, M., Kostiainen, R., Kauppila, T.J., 2015. Analysis of neonicotinoids from plant material by desorption atmospheric pressure photoionization-mass spectrometry. Rapid Commun. Mass Spectrom. 29, 424-430. doi:10.1002/rcm.7123

Wolfender, J.-L., Marti, G., Thomas, A., Bertrand, S., 2015. Current approaches and challenges for the metabolite profiling of complex natural extracts. Journal of Chromatography A, Editors' Choice IX 1382, 136-164. doi:10.1016/j.chroma.2014.10.091

Yrjönen, T., Eeva, M., Kauppila, T.J., Martiskainen, O., Summanen, J., Vuorela, P., Vuorela, H., 2016. Profiling of Coumarins in Peucedanum palustre (L.) Moench Populations Growing in Finland. Chem. Biodivers. 13, 700-709. doi:10.1002/cbdv.201500198 
Table 1. DAPPI-MS ${ }^{2}$ data of the most intensive ions in the Peucedanum palustre samples.

\begin{tabular}{lll}
\hline Detected ion & MS ${ }^{2}$ product ions & Suggested identity \\
\hline \multicolumn{2}{l}{ Positive ion mode } & {$[\mathrm{M}+\mathrm{H}]^{+}$of columbianadin } \\
\hline 329 & 229 & {$[\mathrm{M}+\mathrm{H}]^{+}$of umbelliprenin } \\
367 & $383,365,221,203,163,161,147,133,119$ & Unidentified $^{2}$ \\
$401^{\text {a }}$ & 229 & {$[\mathrm{M}+\mathrm{H}]^{+}$of peulustrin } \\
445 & 133,99 & \\
\hline Negative ion mode & Unidentified \\
\hline 215 & $223,197,123$ & Unidentified \\
$297^{\mathrm{a}}$ & $365,349,311$ & Unidentified \\
367 & $399,361,343,317,299,271,227$ & {$[\mathrm{M}-\mathrm{H}]^{-}$of peulustrin } \\
443 & & \\
\hline
\end{tabular}

a detected only with toluene 


\section{Figure captions}

Fig. 1. Schematic of the DAPPI source with a Peucedanum palustre leaf sample fixed on a glass microscope slide and placed on the sampling mount

Fig. 2. Analysis of an umbel sample by DAPPI-MS in positive ion mode using a) acetone, and b) toluene as the dopant, and in c) negative ion mode using acetone as the dopant

Fig. 3. Chemical structures and molecular weights of columbianadin, peulustrin and umbelliprenin

Fig. 4. Tentative fragmentation pattern for the $[\mathrm{M}-\mathrm{H}]^{-}$ion of peulustrin in negative ion DAPPI-MS ${ }^{2}$ 


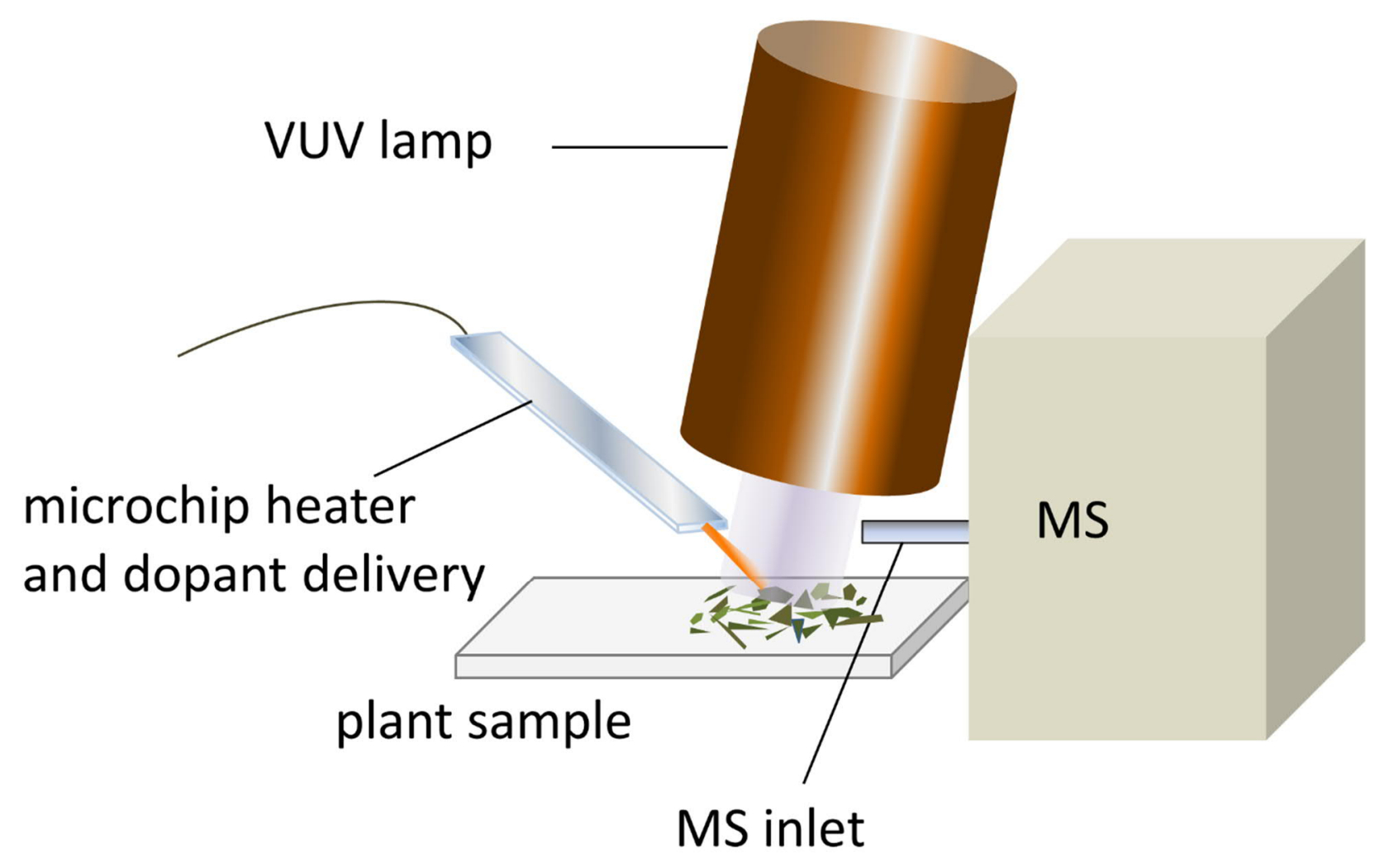

Fig. 1. (color online) 
Intens.

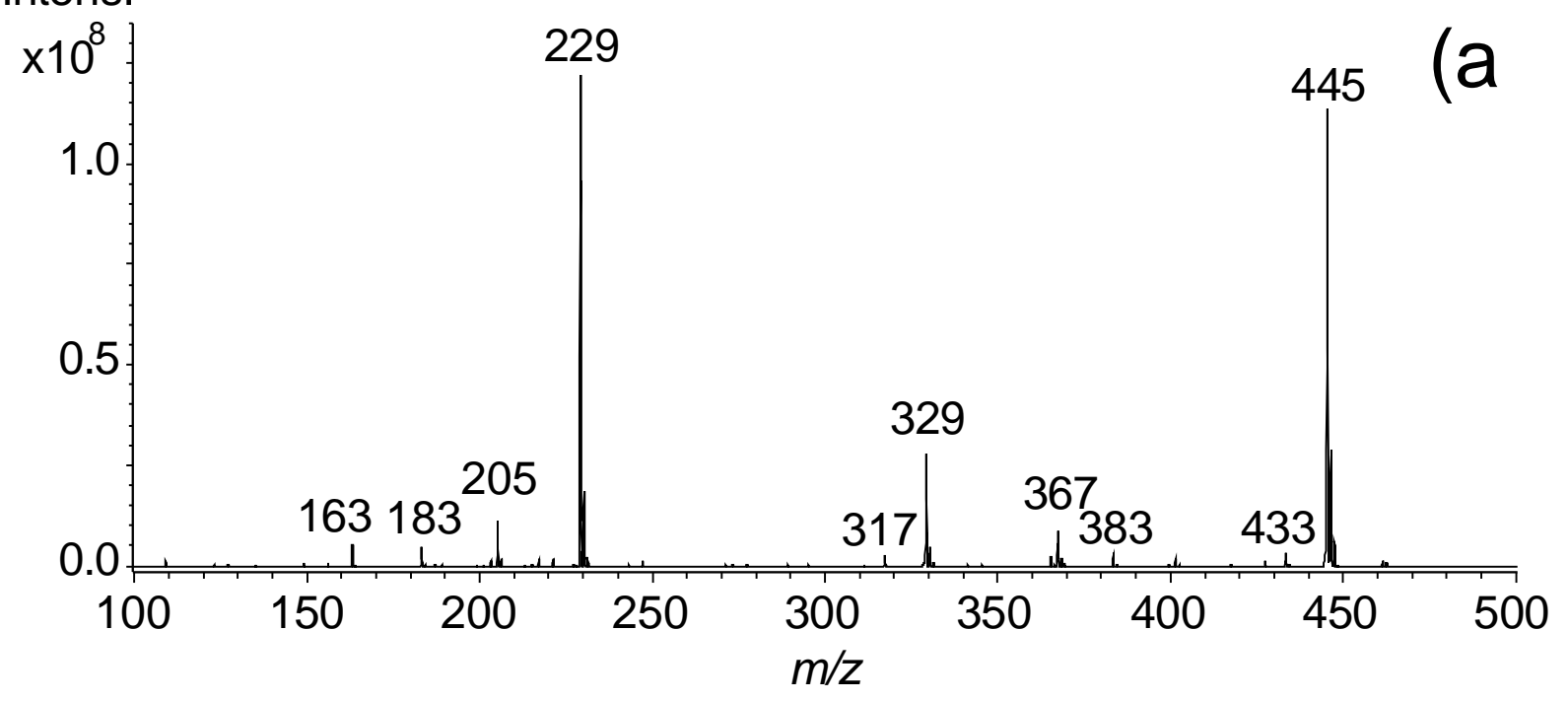

Intens.

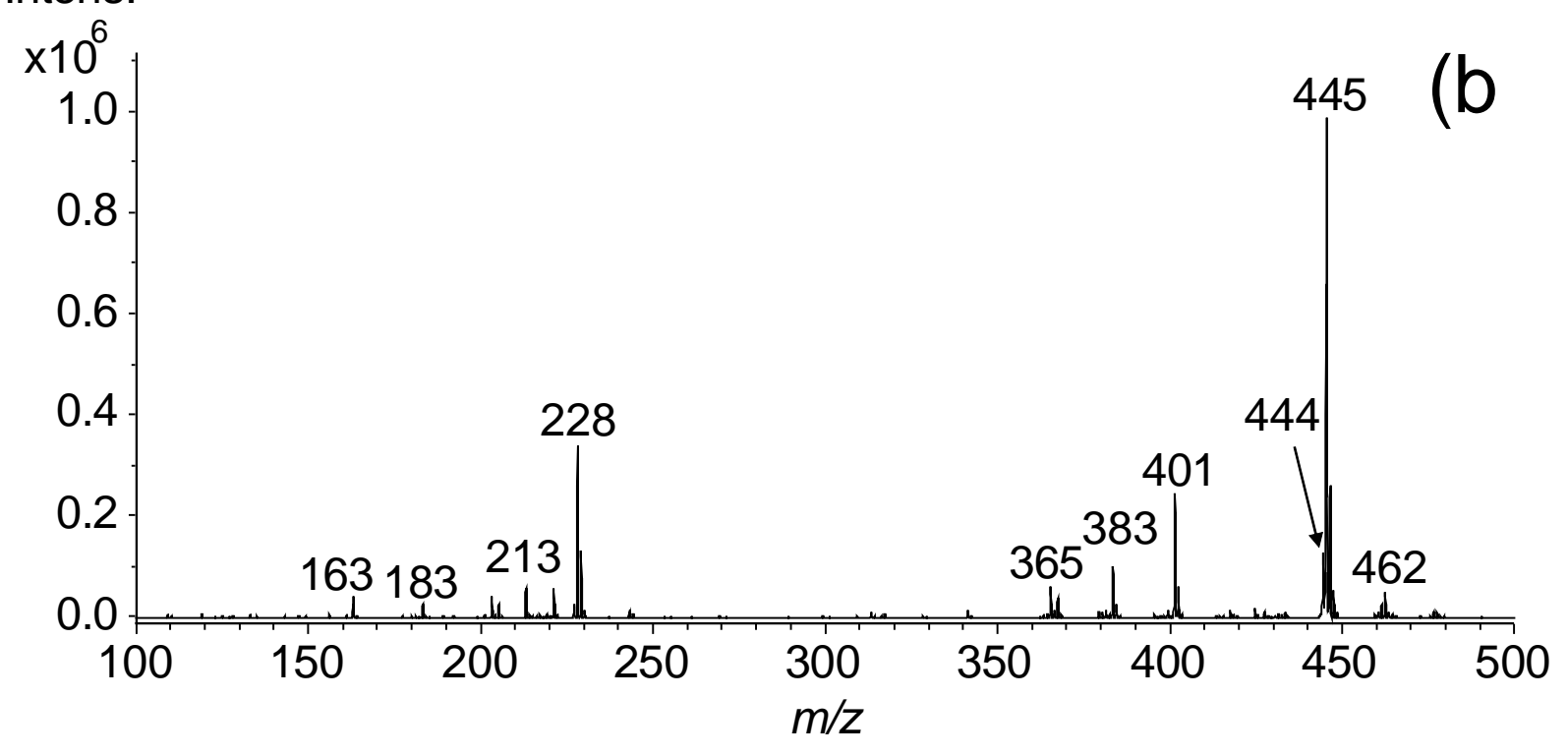

Intens.

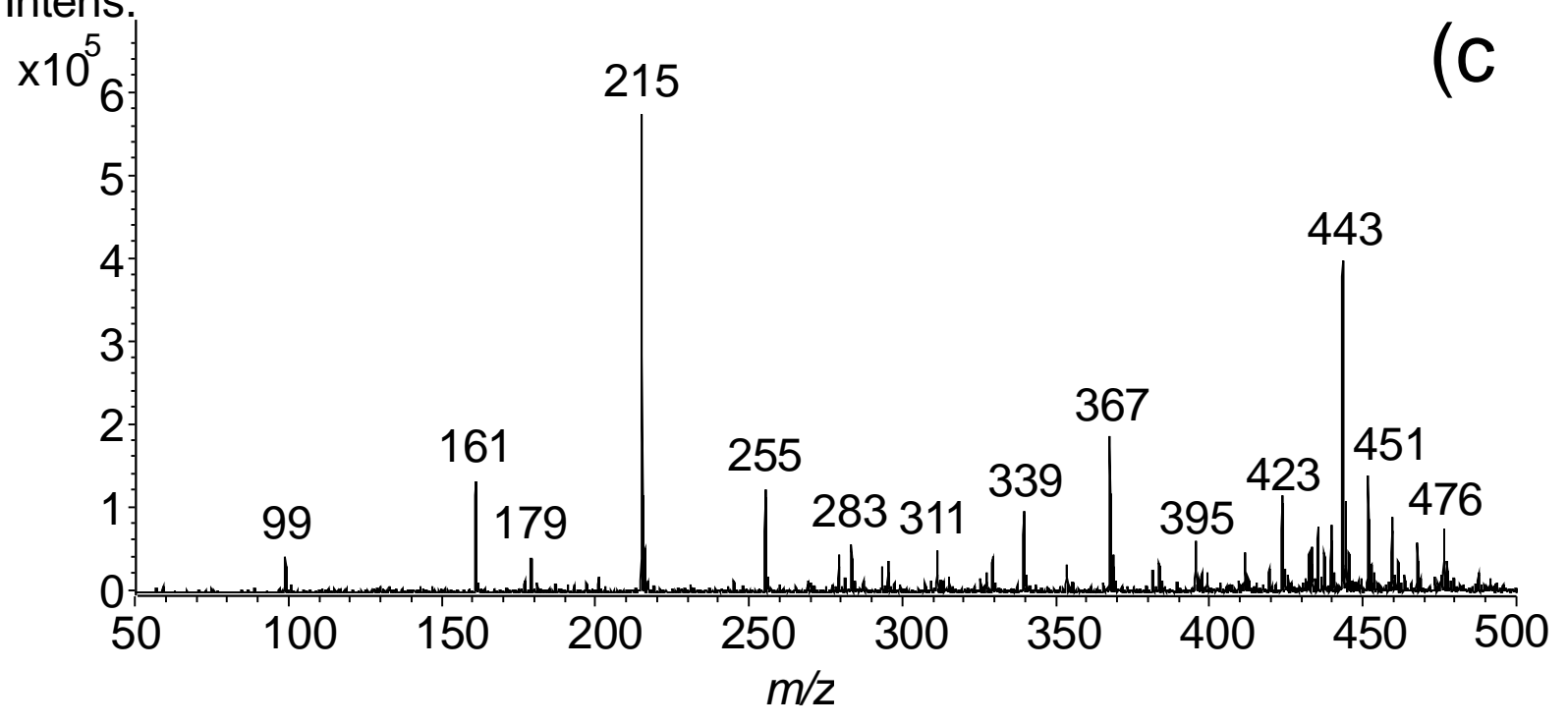

Fig. 2. 


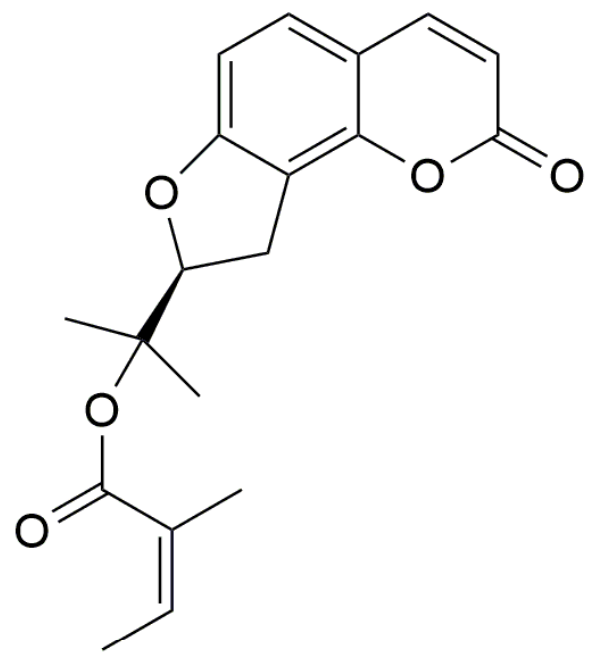

Columbianadin Mr 328

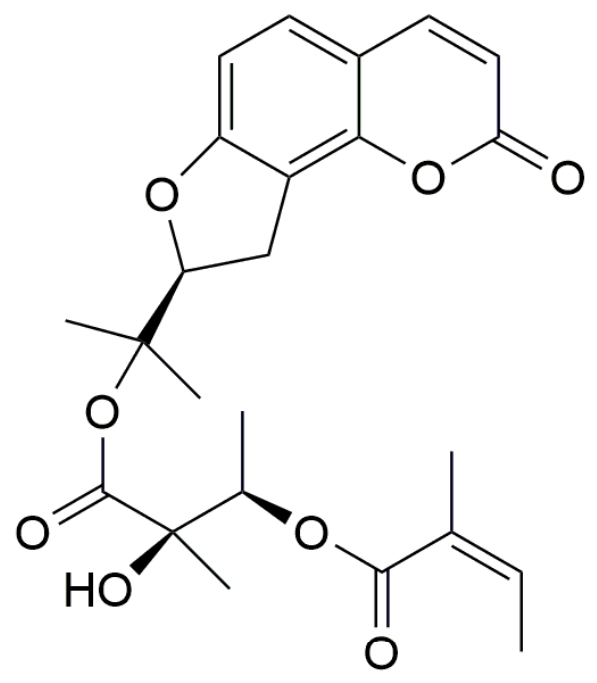

Peulustrin Mr 444<smiles>CC(C)=CCC/C(C)=C/CC/C(C)=C/COc1ccc2ccc(=O)oc2c1</smiles>

Fig. 3. 


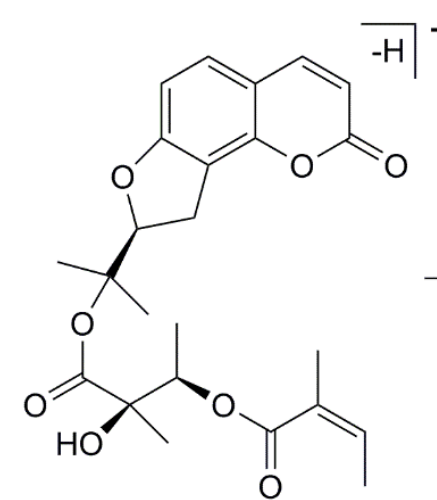

$-\mathrm{C}_{5} \mathrm{H}_{6} \mathrm{O}$

$\mathrm{m} / \mathrm{z} 443$

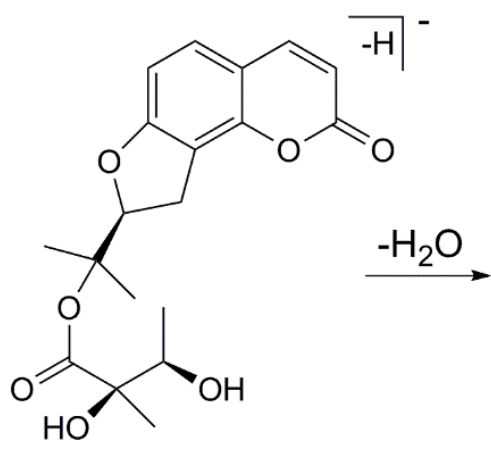

$\mathrm{m} / \mathrm{z} 361$

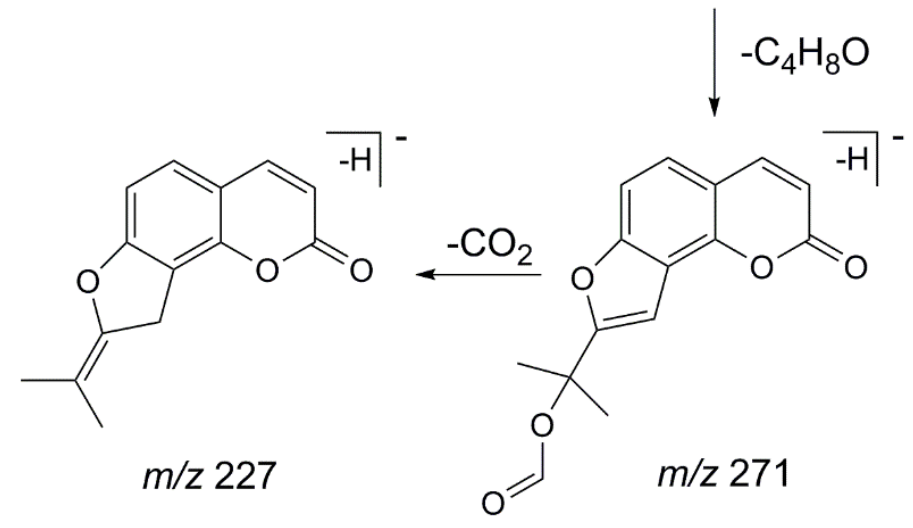

$m / z 343$

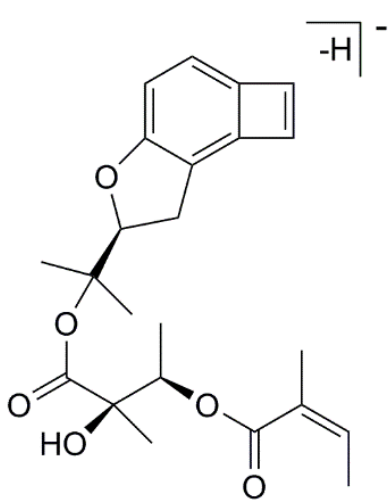

$\mathrm{m} / \mathrm{z} 399$

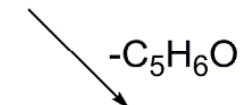

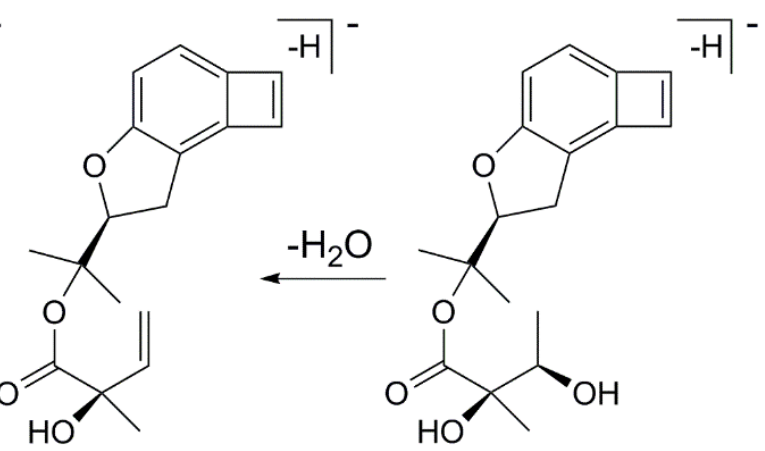

$\mathrm{m} / \mathrm{z} 317$ $m / z 299$ $-\mathrm{C}_{4} \mathrm{H}_{8} \mathrm{O}$

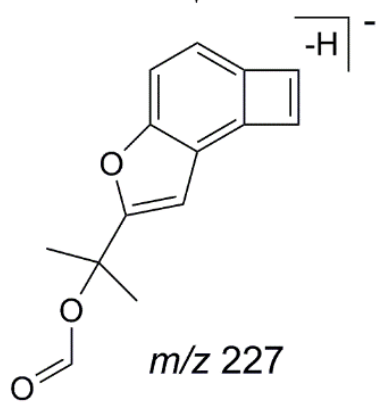

Fig. 4. 